Received: 9 January 2019

Accepted: 1 April 2019

Published online: 12 April 2019

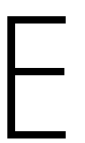

N
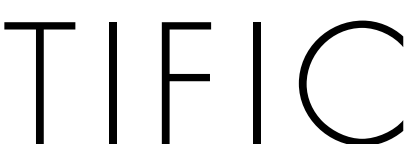

REP

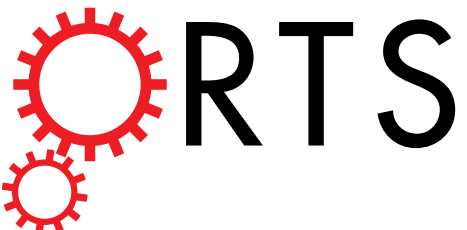

OPEN

Relation between Baseline Total Serum Cortisol Level and Outcome in Pediatric Intensive Care Unit

\author{
Osama E. Bekhit ${ }^{1}$, Shereen A. Mohamed (1) ${ }^{2}$, Remon M. Yousef ${ }^{1}$, Hoiyda A. AbdelRasol ${ }^{3}$, \\ Nirvana A. Khalaf ${ }^{4} \&$ Fatma Salah ${ }^{4}$
}

Elevated cortisol level is an component of the stress response. However, some patients have low cortisol levels; a condition termed: critical illness-related corticosteroid insufficiency (CIRCI). Basal cortisol levels during PICU admission may be related to outcome. This prospective cohort study aimed to assess basal total serum cortisol levels and their relation to outcome in PICU. The study included 81 children over 6 months. Total serum cortisol was assessed using an early morning sample. The severity of illness was assessed using the PRISM-III score. Outcome measures included mechanical ventilation duration, use of inotropic support, length of stay, mortality. Comparison between patients' subgroups according to total serum cortisol levels revealed significantly higher PRISM-III score in patients with total serum cortisol levels. In addition, those patients had a significantly higher mortality rate when compared with patients with low and normal total serum cortisol levels. Multivariate logistic regression analysis recognized high total serum cortisol level and PRISM-III score as significant predictors of mortality. We concluded that PRISM-III score and elevated total serum cortisol levels are significant predictors of mortality in the PICU. Although CIRCI is prevalent in this population, it wasn't associated with an increased mortality rate.

Critical illness entails a complex pathological process that triggers exaggerated inflammatory and stress responses together with systemic dysregulation of endocrine functions. These factors -if not properly managed-ultimately result in impaired tissue perfusion and multi-organ failure ${ }^{1}$. In the context of endocrine response to critical illness, increased levels of the stress hormone cortisol serve to control the stress response and maintain cardiovascular homeostasis ${ }^{2}$.

However, in some situations, cortisol levels fail to surge in response to critical diseases. In 2008, an international task force adopted the term: critical illness-related corticosteroid insufficiency (CIRCI) to describe this condition. Probable causes include central inhibition of adrenocorticotropic hormone (ACTH) synthesis and altered synthesis or metabolism of cortisol $^{3}$. Diagnosis of CIRCI requires random plasma cortisol level of less than $10 \mu \mathrm{g} / \mathrm{dl}$ or cortisol level rise of less than $9 \mu \mathrm{g} / \mathrm{dl}$ over 60 minutes after ACTH injection ${ }^{4}$.

The relation between cortisol response and ICU outcome remains controversial ${ }^{5}$ with some reports documenting the detrimental effects of very high cortisol levels and others blaming low cortisol levels for unfavorable outcome ${ }^{6-8}$.

In pediatric populations, altered cortisol response constitutes a special challenge to the managing teams. However, this issue was rarely investigated in comparison to the frequently published studies on adult patients ${ }^{9}$.

\title{
Aim of Work
}

The aim of this study is to assess basal cortisol levels and their relation to outcome of critically ill children.

\footnotetext{
${ }^{1}$ Pediatric department, Faculty of Medicine, Fayoum University, Fayoum, Egypt. ${ }^{2}$ Pediatric department, Kasr AlAiny Faculty of Medicine, Cairo University, Cairo, Egypt. ${ }^{3}$ Clinical Pathology department, Faculty of Medicine, Fayoum University, Fayoum, Egypt. ${ }^{4} \mathrm{Clinical}$ pathology unit, Research institute of ophthalmology, Giza, Egypt. Correspondence and requests for materials should be addressed to O.E.B. (email:dr_elsayed71@yahoo.com)
} 


\begin{tabular}{|c|c|}
\hline Age (months) median (IQR) & $9.0(3.6-30.0)$ \\
\hline \multicolumn{2}{|l|}{$\operatorname{Sex} n(\%)$} \\
\hline Male & $41(50.6)$ \\
\hline Female & $40(49.4)$ \\
\hline \multicolumn{2}{|l|}{ Cause of admission $\mathrm{n} \%$} \\
\hline CNS & $10(12.3)$ \\
\hline Respiratory & $29(35.8)$ \\
\hline CVS & $9(11.1)$ \\
\hline Sepsis & $15(18.5)$ \\
\hline Others & $18(22.2)$ \\
\hline PRISM-III median (IQR) & $5.0(3.0-8.0)$ \\
\hline \multicolumn{2}{|l|}{ Total cortisol } \\
\hline Median (IRQ) & $29.3(15.2-42.0)$ \\
\hline$<10 \mu \mathrm{g} / \mathrm{dl} \mathrm{n}(\%)$ & $15(18.5)$ \\
\hline $10-34 \mu \mathrm{g} / \mathrm{dl} \mathrm{n}(\%)$ & $38(46.9)$ \\
\hline$\geq 35 \mu \mathrm{g} / \mathrm{dl} \mathrm{n}(\%)$ & $28(34.6)$ \\
\hline \multicolumn{2}{|l|}{ Outcome } \\
\hline Hospital stay (days) Median (IQR) & $6(4.0-8.5)$ \\
\hline PICU stay (days) Median (IQR) & $4(3-7)$ \\
\hline MV (days) Median (IQR) & $4(2.25-4)$ \\
\hline MV days \% from PICU stay Median (IQR) & $20(0-60)$ \\
\hline Inotropic use n (\%) & $79(97.5)$ \\
\hline Mortality n (\%) & $19(23.5)$ \\
\hline
\end{tabular}

Table 1. Patients characteristics. IQR: interquartile range, CNS: central nervous system, CVS: Cardiovascular system, PICU: Pediatric Intensive Care Unit, MV: Mechanical ventilation. PRISM: Pediatric Risk of Mortality.

\section{Patients and Methods}

This prospective cohort study was conducted at pediatric ICUs, Fayoum University Hospital and Aboul-Elrish Pediatric University Hospital, over 6 months period. The study protocol was approved by the Research Ethical Committee of Kasr Alainy Faculty of Medicine, Cairo University and Faculty of Medicine, Fayoum University and in accordance with Declaration of Helsinki for medical research involving human subjects. The research objectives were explained to the patients' guardians and informed consent was taken before patients' enrollment from patients' legal guardians. All patients admitted to PICU, aged from one month to 14 years were included. Patients with known hypothalamic, pituitary, adrenal or severe hepatic diseases, or on corticosteroid treatment or other medications affecting adrenal function in the preceding 3 months were excluded.

Demographic and clinical data were collected. Routine laboratory investigations were performed within the first 24 hours after admission. These included complete blood count, renal profile, coagulation profile, serum albumin, arterial blood gases. Early morning, fasting sample for total serum cortisol was withdrawn. Total serum cortisol levels were assessed using a commercial solid-phase chemiluminescent immunoassay. The reported levels were classified into three categories: $<10 \mu \mathrm{g} / \mathrm{dl}$ (CIRCI), 10-34 $\mu \mathrm{g} / \mathrm{dl}$ (normal range), and $\geq 35 \mu \mathrm{g} / \mathrm{dl}$ (above normal range $)^{10}$.

Severity of critical illness was evaluated using pediatric risk of mortality III score (PRISM-III) ${ }^{11}$. Outcome measures included mechanical ventilation duration, use of inotropic support, PICU length of stay, and PICU mortality.

Statistical analysis was performed using SPSS 15.0 (IBM, Chicago, IL, USA). Data are presented as frequency and percent, mean \pm SD or median and interquartile range (IQR). Comparative statistics were performed using Mann-Whitney U-test, Kruskal-Wallis test, chi-square test, or Fisher's exact test as appropriate. Pearson's or Spearman's correlation coefficients were used to assess the relationships among variables. Logistic regression analysis was used to detect predictors of mortality. Receiver operator characteristic (ROC) curve analysis was utilized to discover reliability of independent variables to predict outcome. $\mathrm{P}<0.05$ was considered significant.

\section{Results}

The present study included 81 children admitted to the PICU over a 6 months period. Basic patients' characteristics are illustrated in Table 1. Comparison between patients' subgroups classified according to basal total serum cortisol levels revealed significantly higher PRISM-III score in patients with cortisol levels $\geq 35 \mu \mathrm{g} / \mathrm{dl}$. In addition, those patients had significantly higher mortality rate when compared with patients with low and normal total serum cortisol levels ( $39.3 \%$ vs $6.7 \%$ and $18.4 \%$ respectively; $\mathrm{p}=0.033)$. No statistically significant differences were noted between patients' subgroups regarding other clinical and outcome parameters (Table 2).

The relation between mortality and total serum cortisol levels was also confirmed in Table 3 that compared the clinical and outcome variables between survivors and non-survivors. The same table also showed significantly higher PRISM III score in non-survivors when compared with survivors. Moreover, Fig. 1 revealed the significant direct correlation between total serum cortisol levels and PRISM-III score $(r=0.415, \mathrm{p}<0.0001)$. 


\begin{tabular}{|c|c|c|c|c|}
\hline & $<10 \mu \mathrm{g} / \mathrm{dl}(\mathrm{n}=15)$ & $10-34 \mu \mathrm{g} / \mathrm{dl}(\mathrm{n}=38)$ & $\geq 35 \mu \mathrm{g} / \mathrm{dl}(\mathrm{n}=28)$ & Pvalue \\
\hline Age (months) Median (IQR) & $8.0(3.0-30.0)$ & $13(4.0-69.0)$ & $7.0(3.0-13.5)$ & $0.156^{\#}$ \\
\hline \multicolumn{5}{|l|}{ Sex n (\%) } \\
\hline Male & $7(46.73)$ & $22(57.9)$ & $12(42.9)$ & $0.455^{\# \#}$ \\
\hline Female & $8(53.3)$ & $16(42.1)$ & $16(57.1)$ & \\
\hline \multicolumn{5}{|l|}{ Cause of admission $n \%$} \\
\hline CNS & $2(13.3)$ & $5(13.2)$ & $3(10.7)$ & $0.949^{\# \#}$ \\
\hline Respiratory & $8(53.3)$ & $10(26.3)$ & $11(39.3)$ & $0.162^{\# \#}$ \\
\hline CVS & $1(6.7)$ & $4(10.5)$ & $4(14.3)$ & $0.741^{\# \#}$ \\
\hline Sepsis & $2(13.3)$ & $7(18.4)$ & $6(21.4)$ & $0.809^{\# \#}$ \\
\hline Others & $2(13.3)$ & $12(31.6)$ & $4(14.3)$ & $0.163^{\# \#}$ \\
\hline PRISM-III Median (IQR) & $4(0-5.0)$ & $5(3.0-8.0)$ & $6(3.0-13.0)$ & $0.023^{\# *}$ \\
\hline \multicolumn{5}{|l|}{ Outcomes } \\
\hline Hospital stay (days) Median (IQR) & $5(4-8)$ & $6(4-7.75)$ & $6(5-9.75)$ & $0.628^{\#}$ \\
\hline PICU stay (days) Median (IQR) & $4(3-7)$ & $4(3-6.25)$ & $5(3-8.75)$ & 0.302 \\
\hline MV (days) Median (IQR) & $4(4-4)$ & $4(3-4)$ & $3(2-4)$ & $0.079^{\#}$ \\
\hline MV days $\%$ from PICU stay Median (IQR) & $0(0-60)$ & $10(0-33.93)$ & $55.56(0-80)$ & 0.277 \\
\hline Inotropic use n (\%) & $14(93.3)$ & $38(100.0)$ & 27 (96.4) & $0.333^{\# \#}$ \\
\hline Mortality n (\%) & $1(6.7)$ & $7(18.4)$ & $11(39.3)$ & $0.033^{\# \# * *}$ \\
\hline
\end{tabular}

Table 2. Comparison between patients' subgroups according to cortisol levels regarding clinical and outcome parameters. ${ }^{\#}$ Kruskal Wallis test. ${ }^{\#}$ Chi square $\left(\chi^{2}\right)$ test. *Significant.

\begin{tabular}{|c|c|c|c|}
\hline & Survivors $(n=62)$ & Non-survivors $(n=19)$ & P-value \\
\hline Age (months) Median (IQR) & $8.5(4.0-31.5)$ & $10.0(3.0-20.0)$ & $0.725^{\#}$ \\
\hline \multicolumn{4}{|l|}{ Sex n (\%) } \\
\hline Male & $33(53.2)$ & $8(42.1)$ & $0.396^{\# \#}$ \\
\hline Female & $29(46.8)$ & $11(57.9)$ & \\
\hline \multicolumn{4}{|l|}{ Cause of admission $\mathrm{n} \%$} \\
\hline CNS & $6(9.7)$ & $4(21.1)$ & $0.352^{\# \#}$ \\
\hline Respiratory & $23(37.5)$ & $6(31.6)$ & $0.879^{\# \#}$ \\
\hline CVS & $7(11.3)$ & $2(10.5)$ & $1.000^{\# \#}$ \\
\hline Sepsis & $11(17.7)$ & $4(21.1)$ & $0.979^{\# \#}$ \\
\hline Others & $15(24.2)$ & $3(15.8)$ & $0.669^{\# \#}$ \\
\hline Cortisol Median (IQR) & $22.8(10.6-37.5)$ & $43.73(32.0-59.85)$ & $<0.0001^{\# *}$ \\
\hline PRISM-III Median (IQR) & $4.0(3.0-6.0)$ & $8.0(6.0-13.0)$ & $<0.0001^{\# *}$ \\
\hline \multicolumn{4}{|l|}{ Outcomes } \\
\hline Hospital stay (days) Median (IQR) & $6(4.0-7.0)$ & $7(3.0-12.0)$ & $0.328^{\#}$ \\
\hline PICU stay (days) Median (IQR) & $4(3-6)$ & $7(3-11)$ & 0.065 \\
\hline MV days \% from PICU stay Median (IQR) & $0(0-46.88)$ & $46.67(0.0-81.36)$ & $0.044^{\# *}$ \\
\hline
\end{tabular}

Table 3. Comparison between survivors and non-survivors regarding clinical and outcome parameters. ${ }^{\#}$ Mann-Whitney $U$ test. ${ }^{\#}$ Chi square $\left(\chi^{2}\right)$ test. *Significant.

Multivariate logistic regression analysis recognized high basal total serum cortisol level and PRISM-III score as significant predictors of mortality (Table 4). At a cut-off of 30.05, total serum cortisol had a sensitivity, specificity, PPV and NPV of $89.5 \%, 64.5 \%, 43.6 \%$ and $95.2 \%$ respectively for prediction of mortality (AUC: $0.783,95 \%$ CI: $0.673-0.893$ ) while PRISM III score had correspondent values of $84.2 \%, 66.1 \%, 43.3 \%$ and 93.2 at a cut-off of 5.5 (AUC: $0.806,95.0 \%$ CI: 0.681-0.932). Combined total serum cortisol and PRISM III had an AUC of 0.838 (95\% CI: 0.721-0.956) (Table 5, Fig. 2).

\section{Discussion}

The reported mortality rate in the present cohort was $23.5 \%$. Previous studies documented mortality rates ranging from $0.5 \%$ to $50.0 \%$ depending on the underlying disease, its severity, and most importantly the national income and development ${ }^{12-17}$. Our study identified elevated PRISM-III score and elevated total serum cortisol levels as significant predictors of mortality using univariate and multivariate analyses. Moreover, ROC curve analysis revealed that total serum cortisol level of $30 \mathrm{mcg} / \mathrm{dL}$ at admission had a good discriminative power for mortality (sensitivity $89.5 \%$ and specificity $64.5 \%$ ). 


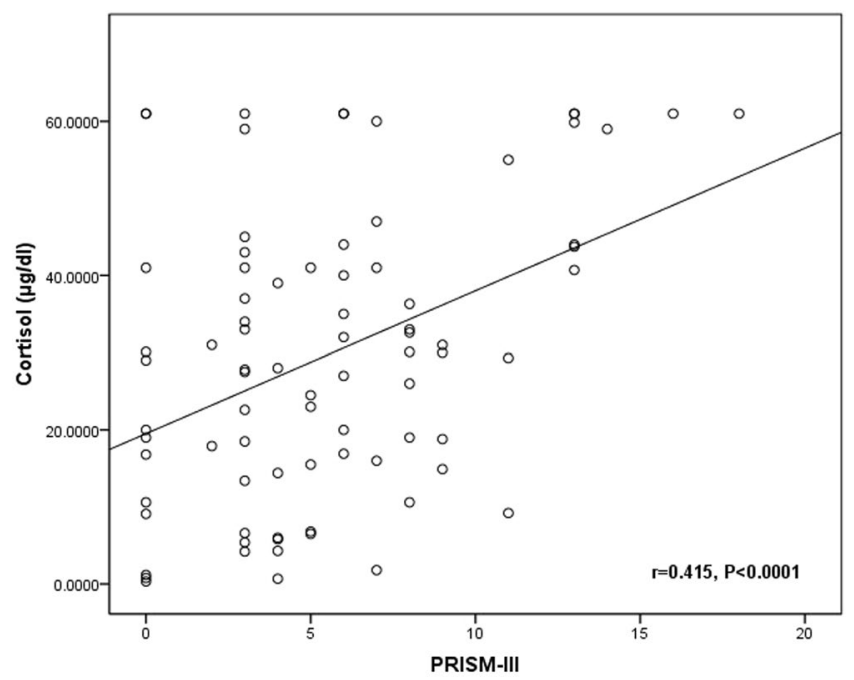

Figure 1. Correlation between Cortisol \& PRISM-III.

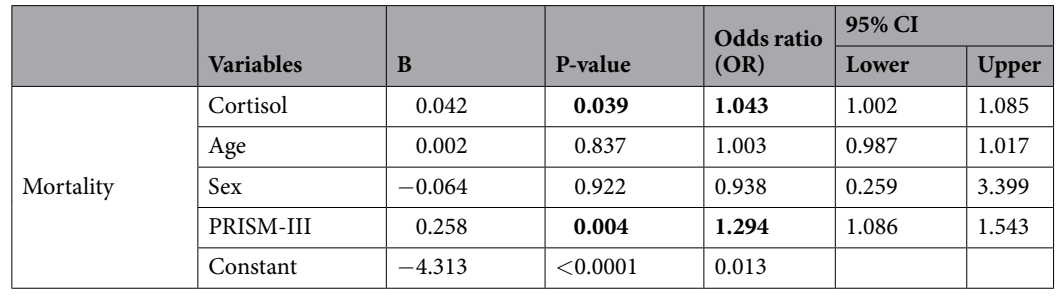

Table 4. Multiple logistic regression.

\begin{tabular}{|l|l|l|l|l|l|}
\hline & Cut-off point & Sensitivity & Specificity & PPV & NPV \\
\hline Cortisol & 30.05 & 89.5 & 64.5 & 43.6 & 95.2 \\
\hline PRISM-III & 5.5 & 84.2 & 66.1 & 43.3 & 93.2 \\
\hline
\end{tabular}

Table 5. Validity of cortisol and PRISM-III for prediction of mortality.

This is in line with previous conclusions highlighting the relation between PRISM-III score and mortality rate $^{18,19}$. Also, a recent study noted increased mortality rate among children with basal cortisol above $600 \mathrm{nmol} / \mathrm{L}^{20}$. Moreover, the study of Nichols et al. ${ }^{21}$ on critically ill children with catecholamine dependent septic shock documented an association between higher total serum cortisol levels $(\geq 18 \mu \mathrm{g} / \mathrm{dL})$ and more severe illness. They also noted that administration of stress dose hydrocortisone in children with low cortisol levels was associated with higher mortality rate. In contrast, another study revealed no correlation between serum cortisol and mortality ${ }^{9}$.

The association between increased cortisol levels and high mortality rate may be explained by the altered cortisol metabolism and disturbed negative feedback mechanism controlling cortisol levels ${ }^{22}$. Probably, these effects are mediated through the rise proinflammatory cytokines release during exaggerated inflammatory response related to disease severity ${ }^{23,24}$. This conclusion is supported by the elevated PRISM-III scores in patients with high cortisol levels and the significant correlation between cortisol levels and PRISM-III scores reported by the current study.

In our study, the prevalence of CIRCI was $18.5 \%$ in comparison to $25.0 \%$ in another study on PICU patients with pediatric acute lung injury/acute respiratory distress syndrome ${ }^{25}$ and $39.6 \%$ and $44.4 \%$ in patients with severe sepsis and septic shock respectively ${ }^{26}$. In addition, our study found no association between CIRCI and the reported mortality rate in accordance with a previous study ${ }^{27}$.

Of note, patients with normal total serum cortisol levels had significantly higher mortality rate than those with CIRCI. A probable explanation for this is the significantly higher PRISM-III score in the former patients' subgroup.

Conclusions of the present study are limited by the relatively small sample size. Considering the wide range of cortisol levels reported in the studied patients, it may be useful to add a control group of healthy volunteers.

\section{Conclusion}

PRISM-III score and elevated basal total serum cortisol levels are significant predictors of mortality in the PICU. Although, CIRCI is prevalent in this population, it wasn't associated with increased mortality rate. 


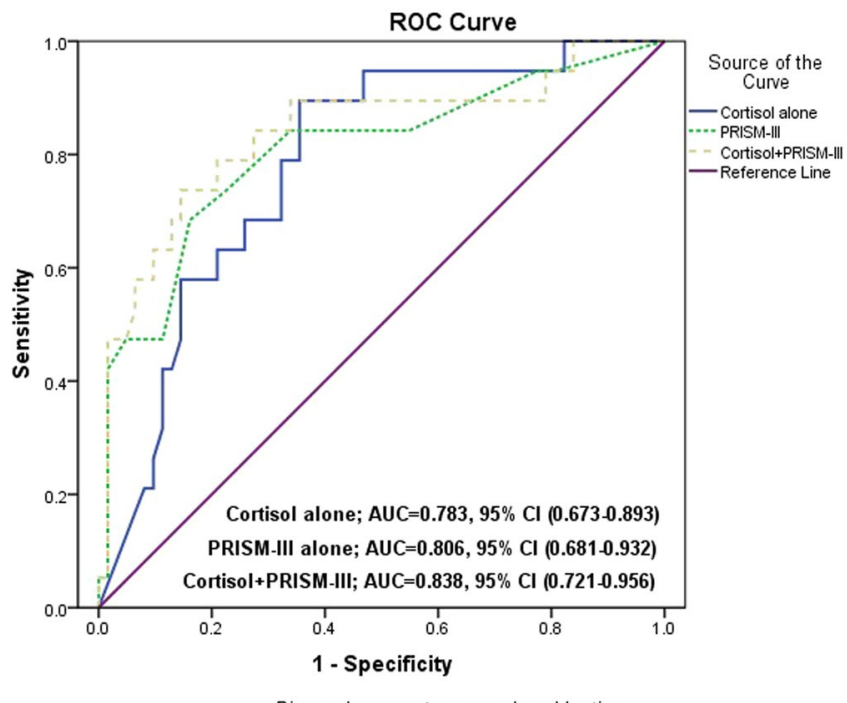

Figure 2. ROC curve for predictors of mortality.

\section{Data Availability}

All data generated or analyzed during this study are included in this published article.

\section{References}

1. Bonardo, D., Paleari, S. \& Vismara, S. The non-linear relationship between managerial ownership and firm performance. Corporate Ownership and Control 4, 18-29 (2007).

2. Arafah, B. M. Review: Hypothalamic pituitary adrenal function during critical illness: Limitations of current assessment methods. J. Clin. Endocrinol. Metab. 91, 3725-3745 (2006).

3. Marik, P. E. et al. Recommendations for the diagnosis and management of corticosteroid insufficiency in critically ill adult patients: Consensus statements from an international task force by the American College of Critical Care Medicine. Crit. Care Med. 36, 1937-1949 (2008).

4. Annane, D. et al. Correction to: Guidelines for the diagnosis and management of critical illness-related corticosteroid insufficiency (CIRCI) in critically ill patients (Part I): Society of Critical Care Medicine (SCCM) and European Society of Intensive Care Medicine (ESIC. In Intensive Care Medicine 44, 401-402 (2018).

5. Menon, K. et al. A prospective multicenter study of adrenal function in critically ill children. Am. J. Respir. Crit. Care Med. 182, 246-251 (2010).

6. Vanhorebeek, I. \& Van Den Berghe, G. The neuroendocrine response to critical illness is a dynamic process. Critical Care Clinics 22 , 1-15 (2006).

7. Annane, D. et al. Effect of treatment with low doses of hydrocortisone and fludrocortisone on mortality in patients with septic shock. J. Am. Med. Assoc. 288, 862-871 (2002).

8. Sam, S., Corbridge, T. C., Mokhlesi, B., Comellas, A. P. \& Molitch, M. E. Cortisol levels and mortality in severe sepsis. Clin. Endocrinol. (Oxf). 60, 29-35 (2004).

9. Aydin, B. K. et al. Evaluation of endocrine function in children admitted to pediatric intensive care unit. Pediatr. Int. 56, 349-353 (2014).

10. Hebbar, K. B., Petrillo, T. \& Fortenberry, J. D. Adrenal insufficiency and response to corticosteroids in hypotensive critically ill children with cancer. J. Crit. Care 27, 480-487 (2012).

11. Pollack, M. M., Patel, K. M. \& Ruttimann, U. E. PRISM III: An updated pediatric risk of mortality score. Crit. Care Med. 24, 743-752 (1996).

12. Barhight, M. F. et al. Increase in chloride from baseline is independently associated with mortality in critically ill children. Intensive Care Med. 44, 2183-2191 (2018).

13. Punchak, M. et al. Epidemiology of Disease and Mortality From a PICU in Mozambique. Pediatr. Crit. Care Med. 19, e603-e610 (2018).

14. Wu, Z. et al. Accuracy Comparison Between Age-Adapted Sofa and Sirs in Predicting In-Hospital Mortality of Infected Children at China's PICU. Shock 11, 11 (2018).

15. Canarie, M. F. et al. Predictors of mortality in a paediatric intensive care unit in Kigali, Rwanda. Paediatr. Int. Child Health 37, 109-115 (2016)

16. Hon, K. L. et al. Mortality, length of stay, bloodstream and respiratory viral infections in a pediatric intensive care unit. J. Crit. Care 38, 57-61 (2017)

17. Verlaat, C. W. et al. Factors Associated with Mortality in Low-Risk Pediatric Critical Care Patients in the Netherlands. Pediatr. Crit. Care Med. 18, e155-e161 (2017).

18. Salah Meligy, B., Kamal, S. \& Awad El Sherbini, S. Mechanical ventilation practice in Egyptian pediatric intensive care units. Electron. physician 9, 4370-4377 (2017).

19. Kim, M. J. et al. Serum anion gap at admission as a predictor of mortality in the pediatric intensive care unit. Sci. Rep. 7 (2017).

20. Levy-Shraga, Y. et al. Elevated Baseline Cortisol Levels Are Predictive of Bad Outcomes in Critically Ill Children. Pediatr. Emerg. Care 34, 613-617 (2018).

21. Nichols, B., Kubis, S., Hewlett, J., Yehya, N. \& Srinivasan, V. Hydrocortisone Therapy in Catecholamine-Resistant Pediatric Septic Shock: A Pragmatic Analysis of Clinician Practice and Association with Outcomes. Pediatr. Crit. Care Med. 18, e406-e414 (2017).

22. Mesotten, D., Vanhorebeek, I. \& Van Den Berghe, G. The altered adrenal axis and treatment with glucocorticoids during critical illness. Nature Clinical Practice Endocrinology and Metabolism 4, 496-505 (2008). 
23. Bornstein, S. R., Engeland, W. C., Ehrhart-Bornstein, M. \& Herman, J. P. Dissociation of ACTH and glucocorticoids. Trends in Endocrinology and Metabolism 19, 175-180 (2008).

24. Bhatia, R., Muraskas, J., Janusek, L. W. \& Mathews, H. Measurement of the glucocorticoid receptor: Relevance to the diagnosis of critical illness-related corticosteroid insufficiency in children. Journal of Critical Care 29, 691.e1-691.e5 (2014).

25. Samransamruajkit, R., Jitchaiwat, S., Deerojanawong, J., Sritippayawan, S. \& Praphal, N. Adrenal insufficiency in early phase of pediatric acute lung injury/acute respiratory distress syndrome. J. Crit. Care 22, 314-318 (2007).

26. Zhang, Y. et al. Adrenal function evaluation using ACTH stimulation test in children with sepsis and septic shock. Zhonghua Er Ke Za Zhi 46, 328-332 (2008).

27. Balbão, V. M. P., Costa, M. M. A., Castro, M. \& Carlotti, A. P. C. P. Evaluation of adrenal function in critically ill children. Clin. Endocrinol. (Oxf). 81, 559-565 (2014).

\section{Author Contributions}

All authors shared in the study design and reviewed the manuscript, O.B. edited and reviewed the manuscript. S.M. and R.Y. collected the data and drafted the manuscript. H.A. did the statistical analysis and shared in the methods protocol. N.K. and F.S. did the laboratory work.

\section{Additional Information}

Competing Interests: The authors declare no competing interests.

Publisher's note: Springer Nature remains neutral with regard to jurisdictional claims in published maps and institutional affiliations.

(c) (i) Open Access This article is licensed under a Creative Commons Attribution 4.0 International License, which permits use, sharing, adaptation, distribution and reproduction in any medium or format, as long as you give appropriate credit to the original author(s) and the source, provide a link to the Creative Commons license, and indicate if changes were made. The images or other third party material in this article are included in the article's Creative Commons license, unless indicated otherwise in a credit line to the material. If material is not included in the article's Creative Commons license and your intended use is not permitted by statutory regulation or exceeds the permitted use, you will need to obtain permission directly from the copyright holder. To view a copy of this license, visit http://creativecommons.org/licenses/by/4.0/.

(c) The Author(s) 2019 